\title{
EDUCACIÓN, INVESTIGACIÓN Y DESARROLLO SOCIAL
}

(Education, research and social development) Ángel Boza, Juan Manuel Méndez, Manuel Monescillo, María de la O Toscano (Coords.), 2010. Narcea Ediciones, Madrid.

ESCRITA POR Sandra Mireya Saba Rodríguez

Docente - investigadora Universidad Pedagógica y Tecnológica de Colombia UPTC- TUNJA samisaro_1106@hotmail.com

EDUCACIÓN,

INVESTIGACIÓN

Y DESARROLILO

SOCIAL.

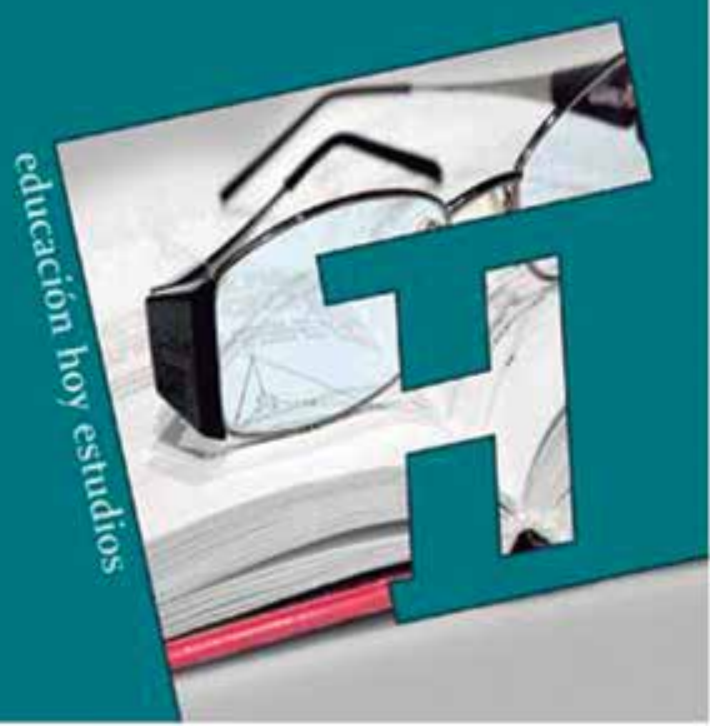




\section{INTRODUCCIÓN}

$E^{\prime}$ libro "Educación, investigación y desarrollo social”, está constituido por el aporte de un grupo de profesionales que trabajan en la educación y la investigación desde una mirada crítica y transparente, por medio de debates, argumentos y relaciones entre las diferentes temáticas, pretendiendo dar soluciones a interrogantes de fondo y de forma, e indagando en nuevos modelos educativos de enseñanza y aprendizaje que conlleven al desarrollo y al planteamiento del quehacer profesional como una obligación en la academia. De la misma forma, el libro analiza el papel de las competencias profesionales en el desarrollo social. En este sentido, se consideran como aspectos fundamentales la formación basada en competencias, el reconocimiento de competencias profesionales y el establecimiento de perfiles competenciales en contextos multiculturales. El libro analiza también las políticas de fomento de la cohesión social desde instituciones internacionales, así como la aportación de las TIC al desarrollo social en términos de impacto. Presenta, finalmente, una novedosa e importante visión de la evaluación como instrumento indispensable para la transformación social, entendiéndola como un proceso interactivo y bidireccional, facilitador de cohesión social. A continuación se hace una reseña de cada uno de los artículos que componen el libro.

\section{Metodologías de INVESTIgACIÓN}

\section{PARA EL DESARROLLO DEL \\ CONOCIMIENTO EN UN CONTEXTO}

\section{MULTICULTURAL}

\section{Autora: Leonor Buendía EISMAN}

Este primer artículo presenta una mirada crítica sobre el aprendizaje desde una visión transcultural, por medio de la interpretación; es por ello que se formula la pregunta sobre la función de las tecnologías de la información TIC, bajo un parámetro intercultural, concluyendo que estas son utilizadas para suplir la necesidad de generar conocimientos en una so- ciedad cambiante, puesto que ellas determinan disciplinas que actualmente forman parte de procesos transdiciplinares, como la biología o cualquier otra ciencia. Se pretende que dentro de las aulas se conecten este tipo de temas dentro de la educación, mediante metodologías de investigación, como el método deductivo, cuyo proceso consiste en sintetizar el estudio de un fenómeno o situación que plantea problemas al investigador, generando hipótesis a partir de dicho fenómeno, deducción de consecuencias y verificación o comprobación de la verdad de los enunciados deducidos, comparándolos con la experiencia. De esta misma forma la autora propone que los modelos de investigación utilizados generan un discurso homogeneizador de cada grupo cultural con base en lo que tienen de común, olvidando los aspectos individuales y dando lugar a que frecuentemente la diversidad intragrupo sea velada por la importancia que actualmente se le brinda a las características comunes.

\section{COMPETENCIAS PROFESIONALES PARA EL DESARROLLO SOCIAL}

Autor: Delio Del Rincón Igea

En el segundo artículo se plantea que el desarrollo social va ligado a la formación; es decir, que actualmente nuestro entorno social, ya sea global, de recursos tecnológicos o cambios de procesos de productos, obedece a procesos paralelos a los procesos de desarrollo de la actual sociedad. El objetivo del autor es el de ofrecer experiencias y reflexiones complementarias de personas expertas en tres ámbitos prioritarios, relacionados con las competencias profesionales, que contribuyen a fomentar el desarrollo social: formación en competencias, reconocimiento de competencias profesionales y perfiles competenciales. El autor propone que las competencias constituyen un conjunto de conocimientos, habilidades o procedimientos, capacidades y actitudes, conexionados y complementarios entre sí, de tal manera que, movilizados al mismo tiempo y de forma interrelacionada, permiten efectuar tareas o hacer frente a situaciones diversas de forma eficaz; 
asimismo, hace énfasis en que ser competente es ser capaz de actuar con idoneidad dentro de una situación profesional; es decir, tomar correctas iniciativas de acción y movilizar un conjunto apropiado de recursos. De la misma forma, tener competencia es disponer de los recursos necesarios para actuar con habilidad, como en efecto puede ocurrir dentro de una situación laboral. Al respecto del tema del desarrollo competencial y la calidad de los servicios y programas de orientación e inserción laboral, el autor menciona que los profesionales no se aplican sin conocimientos, sino que sus poseedores, en este caso los preparadores laborales, los incorporan siempre a una organización cuyo funcionamiento condiciona su desarrollo profesional y su rendimiento como trabajadores.

\section{EVALUACIÓN PARA}

\section{LA TRANSFORMACIÓN SOCIAL}

Autora: Flor A. Cabrera Rodríguez

En este trabajo se analiza la teoría de la evaluación para crear, orientar y promover procesos de cambio y transformaciones personales, colectivas o grupos de la sociedad en general. Desde esa perspectiva, el autor relaciona la transformación social con el quehacer evaluativo. Otro de los aspectos sobre los que reflexiona en el artículo es el de la lógica para la evaluación, desde el paradigma de la responsabilidad compartida y la ética, según la cual la realidad se reconoce como múltiple con diferentes formas y maneras de manifestarse para ser construida. El artículo ofrece una visión sobre la relación evaluación y sociedad, que implica a todos los niveles: personas, organizaciones y sociedad, y cómo esta relación es interactiva. De esa forma, es necesario estar alerta a lo que ocurre fuera de la disciplina de estudio, tanto a los cambios sociales como en otros campos del saber, con el fin de dar respuestas creativas y atinadas. Desde esta óptica, se reflexiona sobre cómo se realiza la evaluación, cómo intervienen las distintas partes interesadas, en qué medida se sienten representadas y responsables del proceso, entre otros cuestio- namientos. Los avances que se observan en la evaluación del aprendizaje son colectivos, con procesos internos, abiertos e impredecibles, $y$ se dan con el fin de mejorar y aprender por medio de un espacio de participación democrática que genere e integre significados compartidos y responsabilidad colectiva.

\section{EDUCACIÓN Y FOMENTO}

\section{DE LA COHESIÓN SOCIAL}

Autora: Raquel Amaya Martínez González

El cuarto artículo constituye un tema de constante preocupación en las sociedades democráticas y económicamente desarrolladas por su repercusión en el mantenimiento del bienestar social. El autor reflexiona sobre la familia, desarrollando el concepto de la cohesión social desde la sociología clásica, que implica la inclusión de los miembros a un grupo, al grado de compartir los mismos valores y participar en el mantenimiento y desarrollo del mismo. Mencionando las principales y más comunes definiciones aceptadas desde la Unión Europea -UE y la Comisión Económica para América Latina y el caribe -CEPAL, $y$, no obstante los problemas generales de los indicadores de Laecken, se centra en los aportes educativos, uno primario y otro secundario. Concluye que las perspectivas macro-analíticas, en especial la guía metodológica del consejo de Europa, constituyen una llamada de atención hacia los modelos de convivencia que se dan en las escuelas y hacia la respuesta educativa, que como acompañamiento de la vida de las personas deben asegurar los estados. En las evaluaciones de sistemas educativos hace falta mayor atención a planteamientos acerca del modo en que se produce el hecho educativo en las escuelas.

\section{APORTACIONES DE LAS TIC}

\section{AL DESARROLLO SOCIAL}

Autor: Javier Tejedor Tejedor

El quinto artículo nos habla sobre una sociedad cultural y la disponibilidad de los nuevos medios tecnológicos, los cuales abren nuevas 
puertas de acción social en todos los ámbitos. Las nuevas herramientas conllevan una serie de cambios que afectan los valores, las actitudes, etc.; es por ello que el autor plantea a las TIC, como una revolución importante, la cual ha llevado a grandes descubrimientos, lo que actualmente se llama la revolución digital, y ha invadido todos los campos sociales y culturales, suscitando un gran cambio; por resumirlo de alguna forma, el nuevo orden informativo se ha convertido en motor del cambio social. Como lo menciona el artículo, el docente es un profesional que debe poseer dominio sobre un saber especifico y complejo, que decide con niveles de autonomía sobre contenidos, métodos y técnicas, que elabora estrategias de enseñanza de acuerdo a la heterogeneidad de los alumnos, organizando contextos de aprendizaje, e interviniendo de diferentes formas para favorecer procesos de construcción de conocimientos desde las necesidades particulares de cada uno de los alumnos; es por lo último que deben ser reconocidos como profesionales expertos. Finalmente, el autor propone que se realice una alfabetización mediática como estrategia para la reducción de la brecha digital; este nivel de alfabetización requiere a su vez de otros niveles previos de desempeño en campos específicos; alfabetización informática, alfabetización digital y en las TIC, alfabetización visual y alfabetización política-cultural. Como reflexión final, el autor plantea que no se debe creer que las tecnologías signifiquen necesariamente progreso; ofrecen oportunidades increíbles pero también generan problemáticas que pueden contribuir a incrementar las desigualdades sociales y a poner obstáculos para conseguir objetivos vinculados a la equidad social.

\section{INVESTIGACIÓN, EQUIDAD Y COHESIÓN}

SOCIAL

Autora: Carmen Jiménez Fernández

El último artículo plantea que la educación se convierte en una herramienta importante para superar viejas y nuevas formas de desigualdad y exclusión social, a través del acceso equitativo a una educación de calidad, a lo largo y ancho del sistema educativo; es por ello que la educación, como instrumento de preparación de corto, medio y largo alcance, es una herramienta fundamental del desarrollo, del conocimiento y de la cohesión social, si bien trasciende su carácter instrumental, para adquirir un sentido emancipador y crítico, aglutinador de los diversos escenarios vitales. El autor habla de la cohesión social, que como objetivo ha ido adquiriendo interés en las sociedades complejas y desarrolladas, dados los indicios de racismo y xenofobia percibidos en Europa frente a la creciente diversidad cultural y social, y ante la amenaza de inestabilidad social, en parte consecuencia del aumento de las desigualdades económicas. Desde diferentes planteamientos, la educación aparece como medio fundamental para promover una mayor igualdad de oportunidades para todos, ya directamente a través de la elevación del nivel de renta asociado al nivel cultural, ya a través del desarrollo de valores que hacen que las personas sean más prosociales y participen en mayor medida en redes sociales que propicien la confianza, la tolerancia y el respeto hacia todos los ciudadanos, ya a través del capital social que se genera desde todo lo anterior. Por lo dicho, la investigación pedagógica debe contribuir a este objetivo, haciendo visibles aquellas realidades más alejadas de la equidad y la justicia social, mostrando posibles caminos para la mejora y la innovación educativa 